\title{
Heat Loss May Explain Bill Size Differences between Birds Occupying Different Habitats
}

\author{
Russell Greenberg ${ }^{1 *}$, Viviana Cadena ${ }^{2}$, Raymond M. Danner ${ }^{1,3}$, Glenn TattersalI ${ }^{2}$ \\ 1 Smithsonian Migratory Bird Center, Smithsonian Conservation Biology Institute, National Zoological Park, Washington, DC, United States of America, 2 Department of \\ Biological Sciences, Brock University, St. Catharines, Ontario, Canada, 3 Avian Ecology Group, Department of Biological Sciences, Virginia Polytechnic Institute and State \\ University, Blacksburg, Virginia, United States of America
}

\begin{abstract}
Background: Research on variation in bill morphology has focused on the role of diet. Bills have other functions, however, including a role in heat and water balance. The role of the bill in heat loss may be particularly important in birds where water is limiting. Song sparrows localized in coastal dunes and salt marsh edge (Melospiza melodia atlantica) are similar in size to, but have bills with a $17 \%$ greater surface area than, those that live in mesic habitats (M. m. melodia), a pattern shared with other coastal sparrows. We tested the hypotheses that sparrows can use their bills to dissipate "dry" heat, and that heat loss from the bill is higher in M. m. atlantica than M. m. melodia, which would indicate a role of heat loss and water conservation in selection for bill size.

Methodology/Principal Findings: Bill, tarsus, and body surface temperatures were measured using thermal imaging of sparrows exposed to temperatures from $15-37^{\circ} \mathrm{C}$ and combined with surface area and physical modeling to estimate the contribution of each body part to total heat loss. Song sparrow bills averaged $5-10^{\circ} \mathrm{C}$ hotter than ambient. The bill of $M$. $m$ atlantica dissipated up to 33\% more heat and 38\% greater proportion of total heat than that of $M$. m. melodia. This could potentially reduce water loss requirements by approximately $7.7 \%$.

Conclusions/Significance: This $>30 \%$ higher heat loss in the bill of $M . m$. atlantica is independent of evaporative water loss and thus could play an important role in the water balance of sparrows occupying the hot and exposed dune/salt marsh environments during the summer. Heat loss capacity and water conservation could play an important role in the selection for bill size differences between bird populations and should be considered along with trophic adaptations when studying variation in bill size.
\end{abstract}

Citation: Greenberg R, Cadena V, Danner RM, Tattersall G (2012) Heat Loss May Explain Bill Size Differences between Birds Occupying Different Habitats. PLoS ONE 7(7): e40933. doi:10.1371/journal.pone.0040933

Editor: Andrew Iwaniuk, University of Lethbridge, Canada

Received January 20, 2012; Accepted June 15, 2012; Published July 25, 2012

This is an open-access article, free of all copyright, and may be freely reproduced, distributed, transmitted, modified, built upon, or otherwise used by anyone for any lawful purpose. The work is made available under the Creative Commons CCO public domain dedication.

Funding: Research was supported by the Abbott Endowment, short-term visitor award, and Research Equipment Pool Grants of the Smithsonian Institution. The funders had no role in study design, data collection and analysis, decision to publish, or preparation of the manuscript.

Competing Interests: The authors have declared that no competing interests exist.

*E-mail: greenbergr@si.edu

\section{Introduction}

The avian bill is iconic for how evolution shapes morphology in response to changing environments. Variation within and between bird species' bills conventionally has been interpreted in light of differences in foraging behavior and diet, and studies of the avian bill provide some of the strongest evidence of the effects of food supply on a morphological feature. Indeed, the shape of bills between closely-related species or subspecies has been shown to relate to forage and dietary differences [1-5]. Some studies have gone further and determined the functional basis for differences in bill morphology that relate to differences in diet $[1,6-10]$. Shortterm changes in bill size have been associated with climateinduced changes in resource availability [7] and the addition and subtraction of potentially competitive species [4]. Studies of adaptive radiation and rapid evolution in bill size have become textbook examples of the evolution of ecologically important traits.

The avian bill may also play an important and heretofore under-appreciated role in body temperature regulation. Appendages and other extremities may be a source of particularly intense heat loss and thus a reduction in size will conserve, and an increase will dissipate, a disproportional amount of heat $[11,12]$. Some older papers presented data suggesting a correlation between temperature and bill size within some avian species (e.g., [13]), with larger bills occurring in warmer climates. Symonds et al. [14] analyzed bill size in over two hundred species in several orders of non-migratory birds and found that bill size decreases with low minimum temperature. VanderWerf [15] further documented such a pattern within the elepaios (Chasiempis spp.).

Until recently, however, the possible ecological importance of the bill in thermal balance has not been the focus of much research, possibly because of a belief that the bill is insufficiently vascularized and of too small a size $[16,17]$ to be an important source of heat loss compared to other appendages (such as flippers and ear pinnae of mammals). It is well known, however, that bills grow and wear continuously [18] and that the tissue within the ramphotheca (horny bill covering) is vascularized $[19,20]$. Furthermore, recent thermographic research has revealed that heat loss from bills can be substantial, at least in larger birds [21-23]. 
If bill size is selected for heat dissipation or conservation, then this opens the question of what process during which season drives the evolution of bill size. Although bill size is known to vary seasonally in many birds [18,24], the magnitude of this variation is quite small. So a single bill size might only be able to maximize heat dissipation or minimize heat loss (for a discussion of this trade-off for avian tarsi see [25]). Historically, the relationship between climate and bill size has focused on heat conservation $[13,14]$, with the argument that smaller bills evolve in areas with colder winters. Speakman and Król [26] advocated a greater focus on heat dissipation during periods of resource flush, as opposed to energy acquisition and conservation during resource poor seasons, when attempting to understand adaptations in endotherms. This approach leads to the hypothesis that increased bill size facilitates the loss of excess metabolically produced heat under hot conditions. Scholander [27] dismissed the importance of Allen's rule because of the well-known ability of many larger animals to constrict blood flow to extremities and limit heat loss during periods of cold ambient temperature. By this argument, if birds are indeed able to reduce blood flow to the bill without constraints, then a large bill could evolve to maximize heat dissipation during periods of high temperature with little cost during cold periods. Consistent with this idea, Tattersall et al. [23] demonstrated that adult Toco toucan (Ramphastos toco) were able to shunt blood flow into the tissue underlying the ramphotheca during exposure to high temperatures and reduce flow in the face of cold temperatures.

It is unclear how the studies of heat dissipation, focused on a few desultory taxa, are relevant to all birds. Speakman and Król [26] argued that because of surface to volume ratios, the effects of heat dissipation would be revealed primarily in endothermic animals with large core body size and it is among them where we should expect to find increased heat loss from enlarged extremities. Given Speakman and Krol's [26] emphasis on heat dissipation in large bodied endotherms, it is logical that the documentation of bill vasodilation and heat dissipation has been, thus far, restricted to relatively large-bodied birds.

Heat loss per se, may not be as much of an issue in smaller endotherms [26], but water loss due to evaporation from the skin and respiratory tract can be very high in small endotherms with high metabolic rates, such as passerines [28-30]. Thus, although small birds are less sensitive to thermal stress than larger birds, because of their high surface-to-volume ratio, small birds process much more water on a mass-specific basis than do larger birds. Combined with their large relative surface area, this makes them particularly susceptible to the negative impacts of water loss [30]. Evaporative water loss does not completely eliminate excess metabolic heat when birds experience ambient temperatures above their thermal neutral zone but below their body temperature [31], and the heat that is eliminated through evaporation may come at the expense of overall dehydration. Therefore, alternative ways to dump "dry" heat that do not involve water loss should be advantageous.

If the avian bill can be used as a radiator to expel excess heat under thermally stressful conditions, this function should be particularly important in birds that occupy climatically poorlybuffered habitats where opportunities to escape direct insolation are reduced and freshwater is limited. Larger bill size would allow for the release of a greater amount of "dry heat." Coastal salt marsh and dune-strand habitats are prime examples of environments where birds might experience thermal and water stress. Greenberg and Olsen [32] showed that eleven taxa subspecies or species of tidal marsh sparrows have larger bills than their sister taxa and Greenberg et al. [24] presented a striking correlation between high summer temperature and bill size (corrected for body size variation) among and within species of salt marsh dwelling sparrows (Emberizinae).

To further evaluate the hypothesis that heat dissipation is driving the evolution of bill size in coastal sparrows, data on the thermal properties of the bill must be acquired to support the assumptions of argument, that a significant amount of heat is lost from the bills and that this varies with bill size. In this study, we compared two subspecies of the song sparrow (Melospiza melodia), which occupy thermally divergent habitats in eastern North America; the Atlantic song sparrow (M. m. atlantica) breeds in dune scrub and salt marsh edges along the mid-Atlantic coast, whereas the eastern song sparrow (M. m. melodia) is widespread in urban and suburban gardens and mesic secondary scrub. Using thermal imaging (see Fig. 1 for sample images) under temperature controlled conditions, we addressed the following four questions: 1) Do small birds maintain bill temperatures above ambient? If so, 2) Does the elevated bill temperature lead to a significant amount of heat loss from the bill relative to the entire heat budget? 3) Does the sparrow subspecies in the more thermally stressful and moisture limited environment release more heat from its bill than the subspecies from the more buffered and mesic environment? And 4) Is heat loss temperature dependent, increasing at higher temperatures, and is there evidence of a threshold transition temperature between vasoconstriction and vasodilation?

\section{Results}

\section{Morphological Measurements}

The only significant subspecies difference was in bill size; Atlantic song sparrows averaged $16.7 \%$ greater total surface area (Table 1). Bill cone surface area was also significantly greater in the Atlantic song sparrows (13.1\%). The mean values (99.81 versus $88.19 \mathrm{~mm}^{2}$ ) were similar to those obtained from much larger samples of Atlantic and eastern song sparrows measured in the field (Greenberg et al. unpubl.) where mean bill surface areas

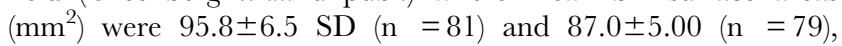
respectively. The bill surface area values for the experimental sparrows corresponded to an estimated 2.05 and $2.38 \%$ of total body surface area for eastern and Atlantic song sparrow, respectively (Table 1).

\section{Bill Temperature and Heat Loss}

Comparison of fit of linear mixed models revealed that both subspecies maintained surface temperatures of the overall bill $\left(T_{\text {bill }}\right)$ and the bill base $\left(T_{\text {base }}\right)$ above ambient $\left(T_{a}\right)$ and that $T_{\text {bill }}$ and $T_{\text {base }}$ increased with $\mathrm{T}_{\mathrm{a}}$ (Fig. 2; Tables 2, 3, Table S3), which resulted in heat loss from the bill (Fig. 3, Tables 4, 5). The relationships between both $T_{\text {bill }}$ and $T_{\text {base }}$ to $T_{a}$ were close to linear for both subspecies. There was strong evidence that $T_{\text {base }}$ was higher in Atlantic song sparrows, particularly at lower temperatures; the model describing an interaction between subspecies and $T_{a}$ was the highest ranked, and according to the evidence ratio (calculated from AICc model weights), was 51 times more likely to be the best model in the set than the highest ranked model without a subspecies term $\left(T_{a}\right.$, Table S2). The top model was 17 times more likely than models without interactions, providing support for an interaction between subspecies and $\mathcal{T}_{a}$. Although subspecies was included in the top model for overall bill temperature, the greater bill temperature found in the Atlantic song sparrow was not well supported (evidence ratio $=1.5$ ). Model average predictions show that song sparrow bills were maintained at $4.7-9.8^{\circ} \mathrm{C}$ over ambient temperatures within the $\mathrm{T}_{a}$ range of the experiment 

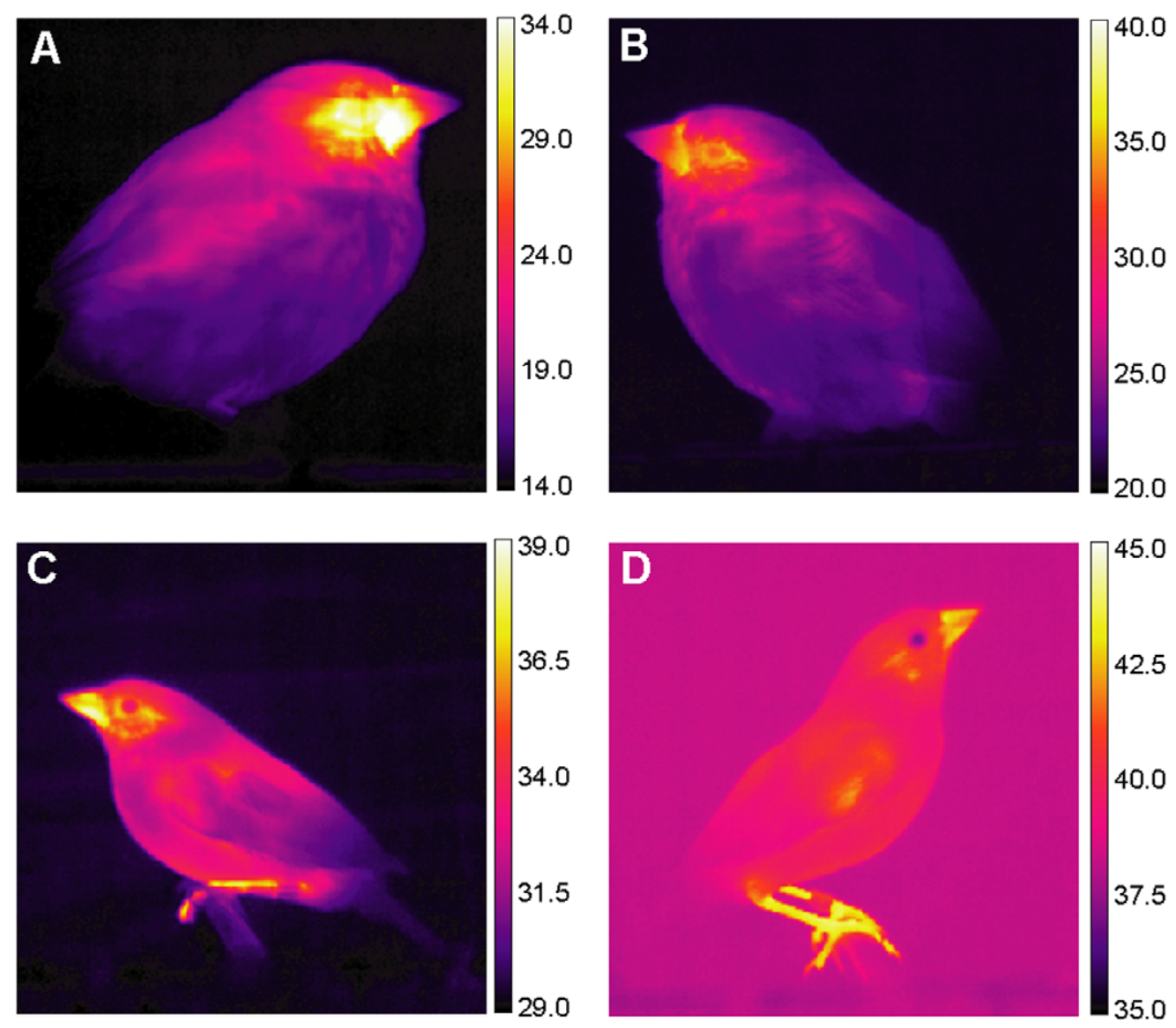

Figure 1. Infrared images of eastern and Atlantic song sparrows. Eastern (A) and Atlantic (B-D) song sparrows were imaged at ambient temperatures of $15(\mathrm{~A}), 21(\mathrm{~B}), 29(\mathrm{C})$, and $37^{\circ} \mathrm{C}(\mathrm{D})$. doi:10.1371/journal.pone.0040933.g001

$\left(15-37^{\circ} \mathrm{C}\right.$, Fig. 4). In contrast, body surface temperature was 2.6- $4.4^{\circ} \mathrm{C}$ over ambient and leg temperature increased nonlinearly relative to ambient temperature (Fig. 3); neither differed by subspecies (evidence ratios for subspecies $=1.4$ and 1.2, respectively, Tables $\mathrm{S} 5$ and $\mathrm{S} 6$ ).
Heat loss through the bill was greater in Atlantic song sparrows than eastern song sparrows, both absolutely $\left(Q_{b i l l}\right.$ heat loss, Fig. $3 \mathrm{~A}$, Table 4, evidence ratio $=50$ ) and in relation to the rest of the body (percent $Q_{\text {bill, }}$ Fig. 3B, Tables 5 and $\mathrm{S} 4$, evidence ratio $=39$ ). Model average predictions show that, in comparison to eastern

Table 1. Mean (and standard deviation) of morphometrics, with P-values based on t-tests (independent samples) for sparrows used in thermal imaging experiments.

\begin{tabular}{|c|c|c|c|c|}
\hline Measurement & Eastern song sparrow & Atlantic song sparrow & P-value (t-test) ${ }^{a}$ & $\begin{array}{l}\text { Percentage } \\
\text { increase }^{b}\end{array}$ \\
\hline Wing Chord (mm) & $65.89(1.19)$ & $63.92(1.44)$ & 0.060 & 2.8 \\
\hline Weight (g) & $18.89(1.27)$ & $19.97(1.05)$ & 0.922 & 5.8 \\
\hline Tarsus (mm) & $20.01(0.74)$ & $19.85(0.89)$ & 1.000 & 0.8 \\
\hline Bill cone area $\left(\mathrm{mm}^{2}\right)$ & $88.19(4.21)$ & $99.89(19.81)$ & 0.015 & 13.1 \\
\hline Total bill area $\left(\mathrm{mm}^{2}\right)$ & $127.46(10.41)$ & $148.70(12.12)$ & 0.011 & 16.7 \\
\hline Leg area $\left(\mathrm{mm}^{2}\right)$ & $240.07(20.87)$ & $241.94(20.61)$ & 1.000 & 0.8 \\
\hline Body area $\left(\mathrm{mm}^{2}\right)$ & $5846.04(149.26)$ & $5852.78(226.03)$ & 1.000 & 0.1 \\
\hline Total bill area as a percent of entire area & $2.05(0.18)$ & $2.38(0.18)$ & 0.015 & 16.0 \\
\hline Leg area as a percent of entire area & $3.86(0.27)$ & $3.87(0.31)$ & 1.000 & 0.4 \\
\hline Body area as a percent of entire area & $94.09(0.29)$ & $93.74(0.45)$ & 0.728 & 0.4 \\
\hline
\end{tabular}




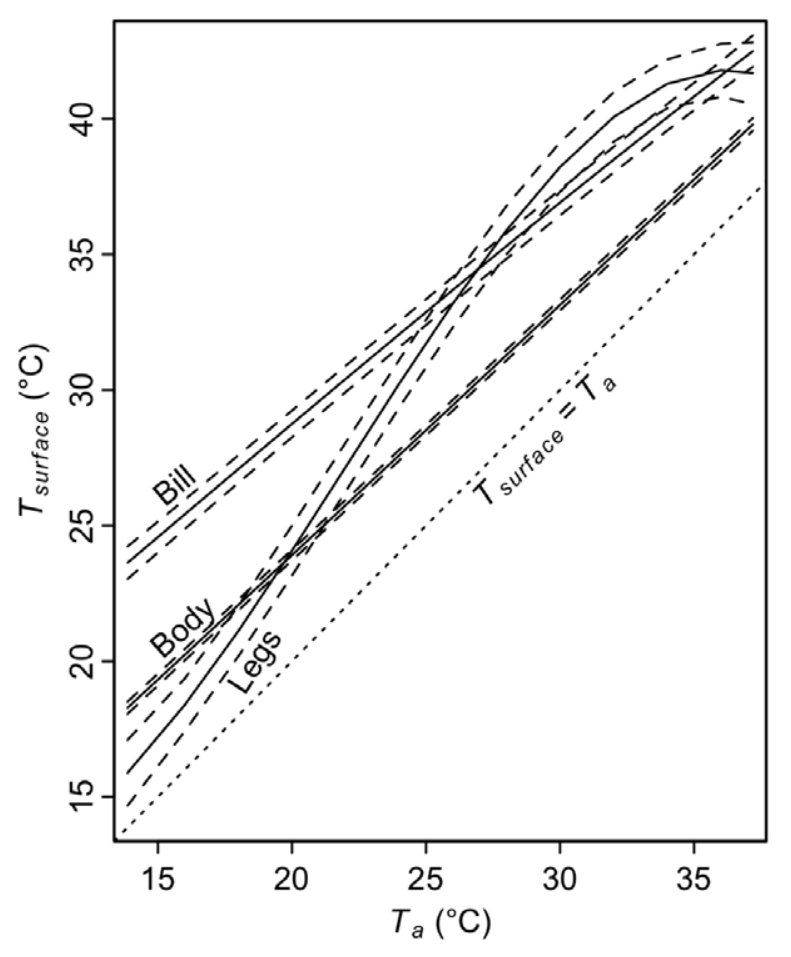

Figure 2. Surface temperature of bill and bill base of song sparrows vs. ambient temperature $\left(T_{a}\right)$. (A) shows values for bill and (B) presents values for bill base. Black lines=model averaged predictions of linear mixed models \pm highest and lowest unconditional standard errors. Gray lines = raw data.

doi:10.1371/journal.pone.0040933.g002

song sparrows, Atlantic song sparrows dissipated 29-33\% more heat through the bill and 29-38\% more heat through the bill as a proportion of total heat lost.

\section{Discussion}

These experiments extend the avian taxa that show evidence of vascular dilation in the bill from a few large bodied birds [21-23] to small birds. Song sparrows have substantially elevated bill temperatures averaging $4.7-9.8^{\circ} \mathrm{C}$ over the range of ambient temperatures presented. The bill accounted for $5.6-10 \%$ of the total heat loss in the two subspecies of song sparrow despite of only making up 2.05 and $2.38 \%$ of total surface area.

The larger bill size and possibly higher bill temperature result in Atlantic song sparrows losing approximately 33\% more heat from its bill than the eastern song sparrow. Taken together with previous findings that coastal salt marsh sparrows have larger bills than their sister taxa [32,33], coastal marsh sparrow taxa that experience hotter summers have larger bills [24], and bill surface area of $M$. melodia in California is correlated to summer high temperatures (Greenberg and Danner unpub. data), the greater heat loss in the Atlantic sparrow provides further evidence that larger bills are selected to dissipate more heat in these thermally stressful and fresh-water limited environments.

Most of the difference in heat dissipation between subspecies can be attributed to the size of the bill. It is unclear from these experiments the degree to which other factors, such as the degree of vasodilation, contributes as well. A greater temperature at the base of the bill of the Atlantic song sparrow is well supported (a model with the interaction between $\mathrm{T}_{a}$ and subspecies was 51 times more likely than the top model without subspecies),
Table 2. Linear mixed models describing the surface temperature of the bill $\left(T_{\text {bill }}\right)$.

\begin{tabular}{|c|c|c|c|c|}
\hline Models & $\mathbf{K}$ & AICc & $\Delta \mathrm{AICc}$ & $\begin{array}{l}\text { AlCc } \\
\text { weight }\end{array}$ \\
\hline $\mathrm{SSP}+T_{a}$ & 6 & 861.232 & 0 & 0.208 \\
\hline $\mathrm{SSP}+T_{a}+T_{a}^{2}$ & 7 & 861.571 & 0.339 & 0.176 \\
\hline $\mathrm{SSP} * T_{a}$ & 7 & 861.730 & 0.498 & 0.162 \\
\hline$T_{a}$ & 5 & 862.071 & 0.839 & 0.137 \\
\hline$T_{a}+T_{a}^{2}$ & 6 & 862.371 & 1.139 & 0.118 \\
\hline $\mathrm{SSP}+T_{a}+T_{a}^{2}+T_{a}^{3}$ & 8 & 863.079 & 1.847 & 0.083 \\
\hline$T_{a}+T_{a}^{2}+T_{a}^{3}$ & 7 & 863.884 & 2.652 & 0.055 \\
\hline $\mathrm{SSP} * T_{a}+\mathrm{SSP} * T_{a}^{2}$ & 9 & 864.018 & 2.786 & 0.052 \\
\hline
\end{tabular}

whereas a greater overall bill temperature has very weak support. The largest blood vessels and greatest blood volume is probably found at the base of the bill (see [20]). We may have detected a well-supported difference in the temperature of the base and not the entire bill because, given that the base is the area with the greatest vasculatization and heat loss, it may be easier to develop an estimate of the effect of size given the amount of individual variation. Evaluating the existence of a difference in overall bill temperature between the subspecies will require further sampling, but such a difference would be an additional avenue for adaptation to thermal environments and thus deserves further investigation. The important point, established in this study, is that an increase in bill size within song sparrows leads to greater heat dissipation.

The amount of heat dissipation from the larger bill of the Atlantic song sparrow should be viewed in terms of marginal values. There is a fixed amount of heat and water that will be lost from all song sparrows. A particular population of song sparrows expanding into a thermally challenging environment will only be able to increase, marginally, from this base value. The expansion of the bill surface needs to be evaluated against other options for marginal increase in heat loss and water conserved. The bill and tarsi are uninsulated and because of their keratin covering, impermeable to evaporative water loss, and hence qualitatively more effective vehicles for dry heat dissipation than other possible surfaces. It is possible that due to constraints in counter current exchange of blood flow and the frequency with which they are covered by contour feathers, that tarsi are less important in heat exchange [14] than the bill. To illustrate the potential importance of the difference in heat loss from the bill to the water budgets we offer the following calculations. The $33 \%$ difference in heat loss

Table 3. Linear mixed models describing surface temperature of the bill base $\left(T_{\text {base }}\right)$.

\begin{tabular}{lllll}
\hline & & & & \\
\hline Models & K & AICc & $\Delta$ AICc & $\begin{array}{l}\text { AICc } \\
\text { weight }\end{array}$ \\
\hline SSP ${ }^{*} T_{a}$ & 7 & 860.717 & 0 & 0.720 \\
SSP $T_{a}+\mathrm{SSP} * T_{a}^{2}$ & 9 & 863.740 & 3.024 & 0.159 \\
\hline
\end{tabular}

Individual is a random effect and square root of activity is a fixed effect in each model. Models with $\Delta \mathrm{AICc}<5$ are included here (see full model set in Table S2). doi:10.1371/journal.pone.0040933.t003 


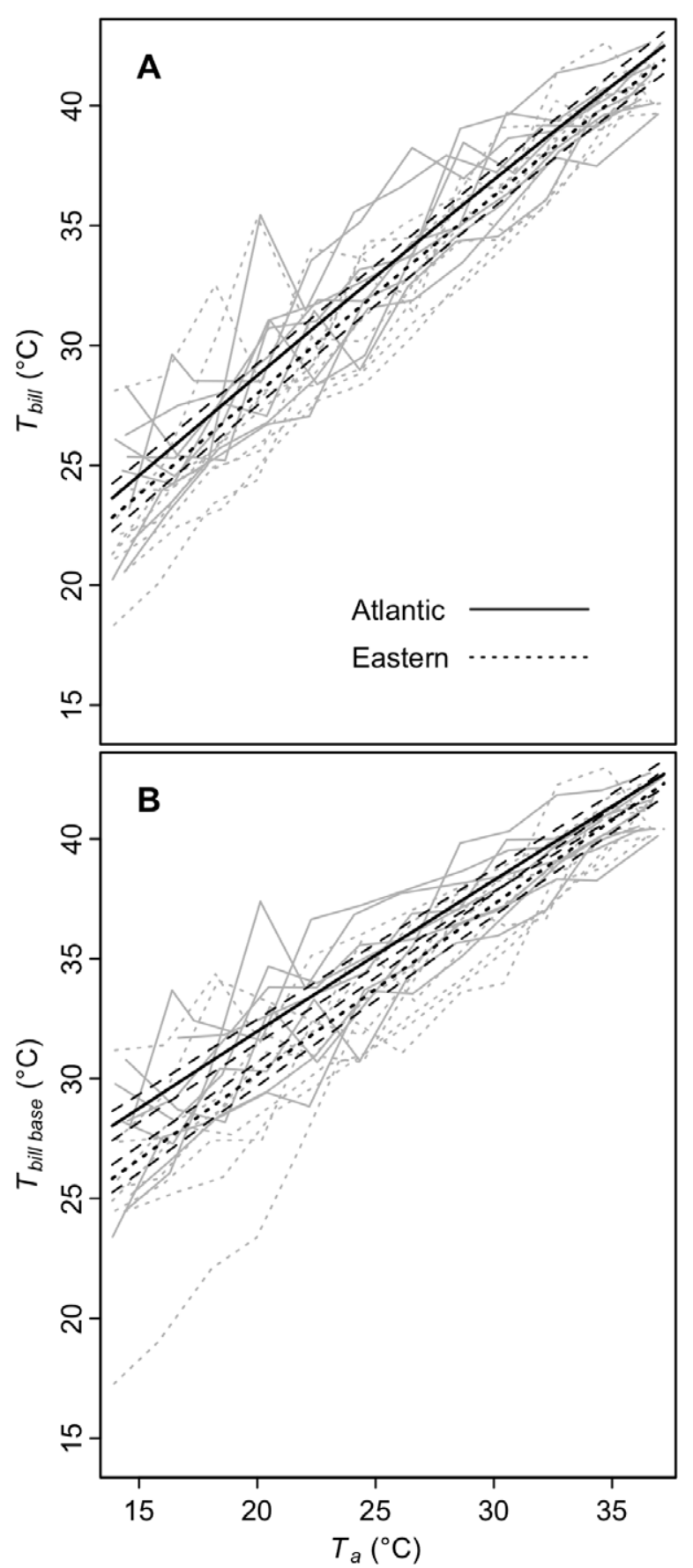

Figure 3. Heat loss through the bill. Total heat loss $\left(Q_{\text {bill }}\right)$ is shown in $(A)$ and the percent of total heat loss through the bill (percent $Q_{\text {bill }}$ is shown in (B). Black lines $=$ model averaged predictions of linear mixed models \pm unconditional standard errors. Gray lines = raw data. doi:10.1371/journal.pone.0040933.g003

from the bill between the Atlantic and eastern song sparrows corresponds to $6.5 \mathrm{~mW}$ of dry heat loss difference. The potential water savings afforded by this would (using a latent heat of vaporization of $2418 \mathrm{~J} / \mathrm{g}$ water; [34]) be $9.7 \mathrm{mg} / \mathrm{h}$, which corresponds to approximately $7.7 \%$ of the evaporative water loss of a similarly sized sparrow at $25^{\circ} \mathrm{C}$ [28].

The increment of heat loss will be important if it further affects some other aspect of the ecology of sparrows that increases fitness. In this case, the increase in bill surface area and heat loss may not
Table 4. Linear mixed models describing heat loss through the bill $\left(Q_{\text {bill }}\right)$.

\begin{tabular}{lllll}
\hline Models & $\mathbf{K}$ & AICc & AAICc & $\begin{array}{l}\text { AICc } \\
\text { weight }\end{array}$ \\
\hline $\mathrm{SSP} * T_{a}$ & 7 & -1578.213 & 0 & 0.462 \\
$\mathrm{SSP}+T_{a}$ & 6 & -1576.144 & 2.070 & 0.164 \\
$\mathrm{SSP} * T_{a}+\mathrm{SSP} * T_{a}^{2}$ & 9 & -1575.855 & 2.358 & 0.142 \\
$\mathrm{SSP}+T_{a}+T_{a}{ }^{2}$ & 7 & -1575.697 & 2.517 & 0.131 \\
$\mathrm{SSP}+T_{a}+T_{a}{ }^{2}+T_{a}{ }^{3}$ & 8 & -1574.063 & 4.150 & 0.058 \\
\hline
\end{tabular}

Individual is a random effect and square root of activity is a fixed effect in each model. Models with $\Delta \mathrm{AICC}<5$ are included here (see full model set in Table S3). doi:10.1371/journal.pone.0040933.t004

cause a measurable decrease in mortality of sparrows, but it may allow an individual to remain active during warmer conditions, thus, longer in the day and later in the breeding season. Provisioning pairs could spend more time gathering food and males can increase their territorial defense and mate-guarding behaviors over more thermally stressed neighbors. It may allow more singing during warmer conditions, which is a large source of respiratory water loss because metabolic rate is increased [35] and respired air during singing bypasses the respiratory turbinates, thus potentially providing the larger billed male with a slight edge over its competitors [24]. As long as the cost of increased bill size is lower than these potential benefits, natural selection could favor the larger billed bird even if the fitness advantages are relatively small.

The monotonic decrease of bill heat loss with increasing ambient temperature (Figure 3A) in both subspecies of song sparrows suggests that the bills of the song sparrows are vasodilated throughout the experimental ambient temperature range. The apparent lack of a distinct vasodilation threshold resulted in a shallow decline in heat loss with increasing temperature caused by the reduced heat transfer potential that occurs when the air and the bill temperatures converge (see [36]). The bills of the song sparrows performed similarly to the immature toucans of the Tattersall et al. [23] study and unlike the adults, which displayed the ability to reduce blood flow to the bill at lower temperatures. In fact, the bills of the sparrows performed unlike the tarsi, which showed a thermal pattern consistent with a constriction/dilation threshold, which is common to many appendages of endothermic animals [21,37-39].

The ecological significance of this pattern is that heat dissipation from the bill becomes a potential cost at lower temperatures. This

Table 5. Linear mixed models describing heat loss through the bill as a percent of heat of heat lost through all body surfaces (percent $\left.Q_{\text {bill)}}\right)$.

\begin{tabular}{|c|c|c|c|c|}
\hline Models & $\mathbf{K}$ & AICc & $\Delta A I C c$ & AICc weight \\
\hline $\mathrm{SSP}+T_{a}+T_{a}^{2}$ & 7 & 784.714 & 0 & 0.358 \\
\hline $\mathrm{SSP}+T_{a}$ & 6 & 785.129 & 0.416 & 0.291 \\
\hline $\mathrm{SSP} * T_{a}$ & 7 & 786.828 & 2.114 & 0.124 \\
\hline $\mathrm{SSP}+T_{a}+T_{a}^{2}+T_{a}^{3}$ & 8 & 786.860 & 2.147 & 0.122 \\
\hline $\mathrm{SSP} * T_{a}+\mathrm{SSP} * T_{a}^{2}$ & 9 & 787.644 & 2.930 & 0.083 \\
\hline
\end{tabular}

Individual is a random effect and square root of activity is a fixed effect in each model. Models with $\triangle \mathrm{AICc}<5$ are included here (see full model set in Table S4). doi:10.1371/journal.pone.0040933.t005 

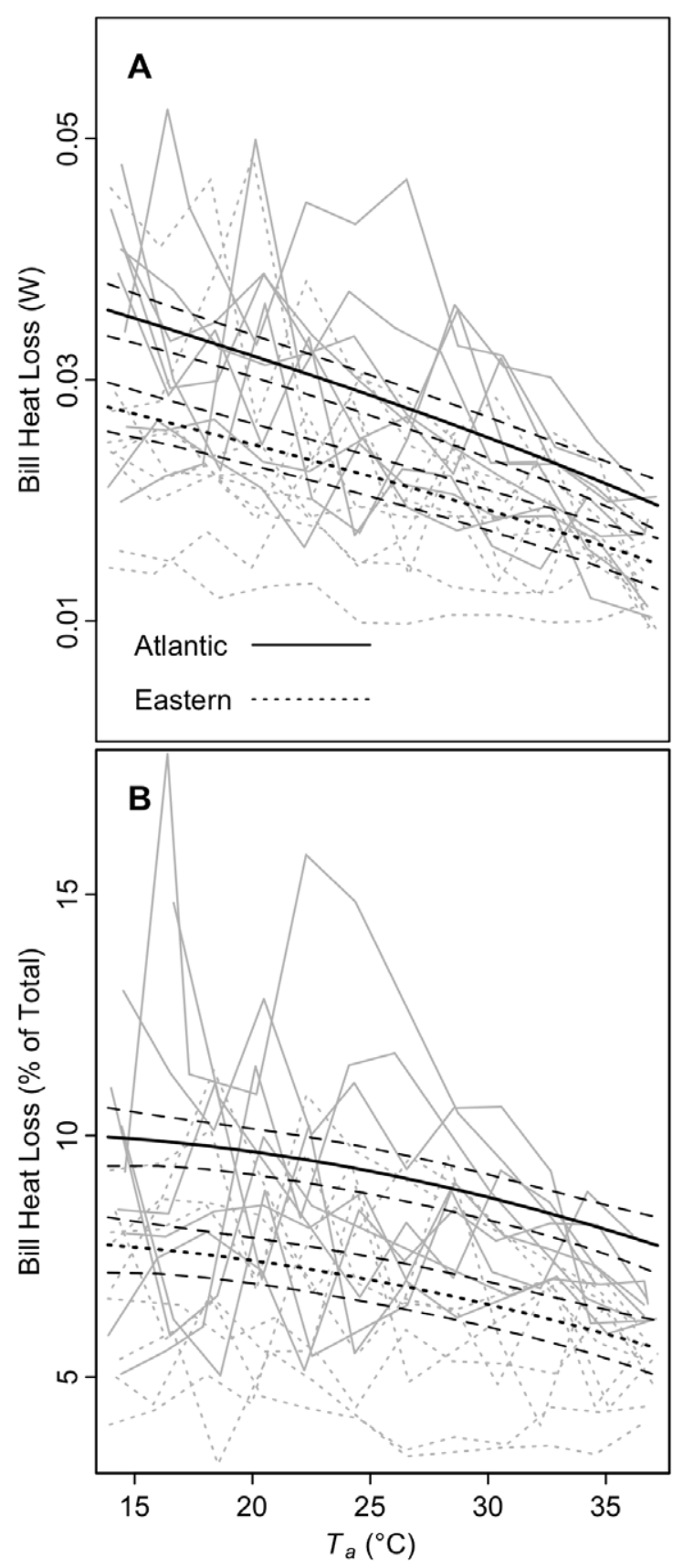

Figure 4. Surface temperatures ( $\left.T_{\text {surface }}\right)$ of the bill, legs (tarsi), and body of both subspecies of song sparrow vs. ambient temperature $\left(T_{a}\right)$. Black lines $=$ model averaged predictions of linear mixed models \pm unconditional standard errors. Body and leg surface temperatures did not differ between subspecies (see text). For bill, only the Atlantic subspecies is shown. Gray dashed line indicates $T_{a}=T_{\text {surface }}$. doi:10.1371/journal.pone.0040933.g004

pattern was tested down to $15^{\circ} \mathrm{C}$, which is well below the minimum critical temperature of the song sparrow's thermoneutral zone $\left(23^{\circ} \mathrm{C}\right.$; $\left.[39,40]\right)$, but should be tested at colder temperatures in the future. If the bill is functioning as a thermal adaptation, then this pattern clearly supports heat dissipation in the summer as the critical process and season. As suggested by Greenberg et al. [24], migration could contribute to the importance of heat dissipation over heat conservation, as different coastal sparrow taxa tend to migrate to warmer wintering grounds and minimum winter temperatures tend to converge. Another hypothesis that can be readily addressed is that patterns of vasoconstriction vary seasonally and constriction occurs at low temperatures during the winter months when heat conservation becomes important.

The reason that the bill does not vasoconstrict at lower temperatures, whereas the legs do, may relate to constraints imposed by bill function and structure. The relatively large jaw muscles are proximate to the base of the bill, where a majority of the heat is dissipated, and where larger blood vessels should be located [20]. Constriction of blood flow to the base of the bill may be constrained by the circulatory requirements of the jaw musculature. The bill needs to function in resource acquisition at all temperatures, and in small temperate zone granivores, feeding rates are probably maximal during the coldest conditions. The legs are more distal to any muscle masses, exhibit countercurrent blood flow, and may be free to constrict their peripheral shunt vessels, allowing the limbs to act alternatively as both conservators and dissipators of heat $[38,41,42]$.

In this study, we compared the heat dissipation by bills of sparrows from two habitats in a controlled environment where some important phenomena, such as radiative heat gain and wind were absent. Future work in the field will be necessary to determine exactly how the convective heat loss we observed in the laboratory functions in the wild. With this caveat, we suggest that the thermographic data provide support for the previously hypothesized mechanism underlying the observation that sparrows in the thermally stressful, fresh-water limited coastal salt marsh/ dune habitats evolved larger bills to dissipate dry heat [24]. Little is known about the diet of the Atlantic song sparrow. So clearly, the possibility that the effect of climate on bill size is indirect, with climate acting through food availability and trophic adaptation, needs to be addressed alongside the physiological approach. The same, however, can be said for studies that focus solely on trophic ecology to explain bill size variation. In light of the issues raised by Speakman and Król [26], the evolution of bill size is an excellent system to evaluate the importance of energy consumption/ conservation versus heat dissipation. Bill size could be shaped by the ability to gain energy through greater efficiency in foraging, the ability to conserve energy by reducing heat loss, or the ability to dissipate heat. Or, as is more likely the case, bill size is the result of adaptive compromises to combinations of these factors.

\section{Methods}

\section{Study Species}

The song sparrow is one of the most widespread, abundant, and polytypic species of North American birds. Most of the 25 recognized subspecies [43] reside in the western portion of the continent. Most of North America supports the eastern song sparrow (M. m. melodia). The Atlantic song sparrow (M. m. atlantica) breeds in a narrow strip of sand dune and salt marsh edge habitat along the outer coast from Long Island to the Outer Banks of North Carolina. Although the ambient temperature of the coastal dune/salt marsh habitat may be slightly cooler than inland sites, the habitat is characterized by little shade, high surface temperatures and irradiance levels, and (in the case of the dunes) generally xeric conditions $[44,45]$.

\section{Field Collection, Care, and Measurement}

Between 15 June and 2 July, 18 male song sparrows were captured by target netting (song playback and a single mist net) and brought to the National Zoological Park, Washington, DC, for thermal imaging experiments. Nine males were captured 
within the breeding range of the Atlantic song sparrow as determined by morphological analysis of museum study skins and recently captured individuals (Greenberg et al. in prep) with six birds obtained at Beach Plum Island, DE $\left(38.81^{\circ},-75.19^{\circ}\right)$ and three from Assateague Island National Seashore (38.21 ${ }^{\circ}$, $-75.16^{\circ}$ ). Nine males were captured within the breeding range of the eastern song sparrow, with four obtained at the National Zoological Park, Washington, DC $\left(38.93^{\circ},-77.05^{\circ}\right)$ and five from Takoma Park, MD $\left(38.99^{\circ},-77.00^{\circ}\right)$.

Upon capture, birds were placed in paper lunch sacks and transported to the holding facility. Sparrows were kept in small chrome wire finch cages $(22 \mathrm{~cm} \times 22 \mathrm{~cm} \times 22 \mathrm{~cm})$ with two elevated $1 \mathrm{~cm}$ diameter dowling perches and a cage floor covered with newspaper. All sparrow cages were placed on metal racks in a single windowless room kept at approximately $25^{\circ} \mathrm{C}$ and a $13 \mathrm{~h}: 11 \mathrm{~h}$ light-dark cycle. Sparrows were provided with ad libitum commercial wild bird mixture with small seeds, 3-5 small mealworms/day, and ad libitum water.

Once during their confinement, we captured and measured morphometrics of the song sparrows. We used digital calipers (0.01 mm precision) to measure wing chord, tarsus length, width, depth (at mid-point) and bill length, depth and width from or at the anterior edge of the nares. These measurements are comparable to those taken from wild-caught birds and are more commonly used in the literature. Additionally, we measured bill length, depth, and width at the base of the bill to obtain a more accurate and complete estimate of bill surface area. Bill cone surface area (comparable to estimates in other studies) measurements were converted to an estimate of surface area of the distal portion of the bill using the following approximate formula for the lateral surface area of a nearly circular elliptical cone $((\mathrm{W}+\mathrm{D}) /$ $4)^{*} L^{*} \pi$. Total bill surface area used the same formula with measurements taken at the base of the bill. Surface area of the legs (tarsi) was estimated using the formula for an elliptical cylinder, $(\pi$ $\left.\left(2\left((\mathrm{w} / 2)^{2}+(\mathrm{d} / 2)^{2}\right)-0.5(\mathrm{w}-\mathrm{d})^{2}\right)^{1 / 2}\right) 1 * 2$, where $w$ is the width, $d$ is the depth and $l$ is the length of the tarsus (the feathered tibia was included in the body surface area). Surface area of the body was estimated according to Walsberg and King [17]: $\mathrm{A}=8.11^{*} \mathrm{~m}^{0.67}$, where $A$ is surface area and $m$ is body mass.

\section{Experimental Procedures}

All experiments were performed inside a temperature-controlled environmental room (Environmental Specialties Inc. model 928WR Comb). The room was equipped with a one way mirror attached to a small office. This allowed us to observe the birds, monitor their behavior and well being, as well as remotely control the thermal camera (see "Collection and Analysis of Thermographic Data" below) and the temperature of the room without disturbing the birds. Ambient temperature $\left(T_{a}\right)$ and relative humidity were recorded throughout the experiments using a Kestrel 4000 portable weather monitoring system.

We performed one experiment on each individual. On the day of an experiment, a bird was transported inside its home-cage to the environmental room. Immediately following transport, food and water dishes were removed from the cage and replaced with a small dish of water, which was sufficient to last the entire experiment. At the beginning of the experiment, a sliding opaque divider was used to confine the bird to one half of the enclosure with access to only one wooden perch located perpendicular to the front of the cage. The thermal camera was located directly in front, allowing constant observation of the bird when standing on the perch.

Once the experimenter had exited the room, the bird was allowed a minimum of $15 \mathrm{~min}$ to habituate to the experimental conditions at $15^{\circ} \mathrm{C}$. The bird was then exposed to $2^{\circ} \mathrm{C}$ step-wise temperature increases from 15 to $37^{\circ} \mathrm{C}$, lasting $15 \mathrm{~min}$ at each temperature. Thermographic data was collected during the last five minutes of exposure to each temperature to allow the birds $10 \mathrm{~min}$ of habituation to the new temperature. At the end of each experiment, the cage divider was removed and the bird was returned to its holding room.

\section{Collection and Analysis of Thermographic Data}

Thermal videos were recorded at 10 frames s$^{-1}$ using a thermal imaging camera (FLIR T-380, FLIR Systems, Inc.) connected to an acquisition program (Examine-R, FLIR Systems, Inc.). Emissivity was assumed to be 0.96 [38]. Five frames were extracted and analyzed from each five-minute video ( 1 frame each minute), using specialized software (Examine-R, FLIR Systems, Inc.). The five frames were selected at the end of each minute interval unless the image was out of focus or the bird was looking away from the camera; the default was to use the temporally closest frame. Regions of interest were digitally drawn to obtain the average surface temperature of the cone of the bill $\left(T_{\text {cone }}\right.$; corresponding to the portion of the bill protruding from the face), the base of the bill ( $\mathcal{T}_{\text {base }}$; corresponding to the of the portion of the bill embedded in the face, approximately $5 \mathrm{~mm}$ contiguous to the cone), the whole bill ( $T_{\text {bill: }}: T_{\text {cone }}$ and $T_{\text {base }}$ together; this was the measurement used for calculations of heat loss, below), the tarsi ( $\mathcal{T}_{\text {legs }}$; we chose to analyze the warmest leg, toes were not included because they could not be seen in the images), and the body ( $\mathcal{T}_{b o d y}$; corresponding to the surface of the largest portion of the body visible in the image).

\section{Estimation of Heat Loss}

We estimated heat loss in Watts $(Q)$ through each major body surface $\left(Q_{\text {bill }}, Q_{\text {tegs }}\right.$ and $\left.Q_{\text {body }}\right)$, total heat loss $\left(Q_{\text {total }}\right)$ by adding values for all body surfaces, and percent $Q_{\text {bill }}$ as $Q_{\text {bill }} / Q_{\text {total }}$. $Q$ of each body part was estimated as described by Tattersall et al. [23], using the following equation:

$$
Q=Q_{r}+Q_{c}
$$

where $Q_{x}$ is the radiative heat exchange and $Q_{c}$ is the convective (forced) heat exchange, such that:

$$
\begin{gathered}
Q_{r}=\varepsilon \sigma A\left(T_{s}^{4}-T_{a}^{4}\right) \\
Q_{c}=h_{c} A\left(T_{s}-T_{a}\right)
\end{gathered}
$$

where $\varepsilon$ is the emissivity for biological tissues (assumed to be 0.96 ; [38], $\sigma$ is the Stefan-Boltzman constant $\left(5.6703 \times 10^{-8}\right), A$ is the surface area $\left(\mathrm{m}^{2}\right)$ of the body part in question, $T_{s}$ is the surface temperature of each specific body region, $T_{a}$ is ambient temperature $\left({ }^{\circ} \mathrm{K}\right)$ and $h_{c}$ is the heat transfer coefficient:

$$
h_{c}=(N u * k) / D
$$

$k$ is the thermal conductivity of air at a particular $T_{a}\left(\mathrm{~W}^{*} \mathrm{~m}^{-1 *} \circ \mathrm{K}\right)$. 


$$
k=0.0241+7.5907 e^{-6 *} T_{a}
$$

$\mathcal{N} u$ is the Nusselt number for each particular body surface.

$$
N u=c R_{e}^{n}
$$

where $c=0.174$ and $n=0.618$ for the bill and legs values $[34,38]$ and $c=0.34$ and $n=0.6$ for the body [46].

$$
R_{e}=(V * D) / v
$$

where $V$ is the air velocity (assumed to be $0.1 \mathrm{~m} / \mathrm{s}$ ), $v$ is the kinematic viscosity of air at each particular $T_{a}$

$$
v=-1.088 e^{-5}+8.85 e^{-8 *} T_{a}
$$

and $D$ is the vertical critical dimension for each body part; $l$ for legs, $d / 2$ for bill and volume ${ }^{1 / 3}$ for body [46]. Volume of each bird was calculated based on mass $(m)$ and density $(\rho)$ of a sparrow $\left(0.913 \mathrm{~g} / \mathrm{cm}^{3} ;\right.$ [47]).

$$
\text { Volume }=m / \rho
$$

\section{Data Analysis}

To test for effects of $T_{a}$ and subspecies on $T_{\text {bill }}, T_{\text {base }}, T_{\text {body }}, T_{\text {legs }}$, $Q_{b i l l}$, and percent $Q_{b i l l}$, we fit linear models to these data with package lme4 [48] in $\mathrm{R}$ [49]. Fixed effects of interest included subspecies (SSP) and $T_{a}$. To test for potential nonlinear effects caused by vasodilation and decreasing heat transfer potential at higher temperatures, we also fit models including $T_{a}^{2}$ and $T_{a}^{3}$. To account for repeated sampling of individuals, we modeled individual as a random effect, which allowed each individual to have a different intercept, but constrained all to have the same slope. Because activity (\# of hops per minute) had a quadratic relationship with $T_{a}$ and did not differ between subspecies (see Text S1, Fig. S1), we included the square root of activity in each model as a fixed effect. Correlograms indicated that none of our data sets were temporally autocorrelated [50].

For environmental variables, we used mean values of $T_{a}$ and relative humidity from the first four minutes of each 5-minute recording period. All environmental values fell within the ranges that both subspecies of song sparrow experience in the wild. Relative humidity during experimentation was negatively correlated to $T_{a}$ and did not differ between subspecies (evidence ratio of $\mathrm{SSP}=0.4$, Table $\mathrm{S} 7$ ), so was not included in further analyses. The saturated model in each model set presented here $\left(\mathrm{SSP} * T_{a}+\mathrm{SSP}\right.$ $* T_{a}^{2}+\operatorname{SSP} * T_{a}^{3}+$ activity $^{1 / 2}+$ random effect of individual) showed homogeneity in the spread of residual values plotted

\section{References}

1. Smith TB (1990) Resource use by bill morphs of an African finch: Evidence for intraspecific competition. Ecology 71: 1246-1257.

2. Remsen JVJ (1991) Community ecology of neotropical kingfishers. Berkeley and Los Angeles: University of California Publications in Zoology. against fitted values, indicating that all models had adequate fit [50].

We determined if subspecies and $T_{a}$ were important predictors of surface temperature and heat loss by calculating evidence ratios (based on AICc values), which compare the probabilities of models with and without those variables [51]. The evidence ratio is calculated as the weight of the model of interest/the weight of the appropriate null model. To estimate values of each response variable at specific temperature and subspecies combinations, we calculated model averaged predictions and unconditional standard errors (which account for model uncertainty) with the package AICcmodavg [52] in R.

\section{Supporting Information}

Figure S1 Activity levels vs. ambient temperature $\left(T_{a}\right)$. Black line $=$ model predictions for both subspecies combined. Gray lines $=$ raw data.

(TIFF)

Table S1 Linear mixed models describing the surface temperature of the bill $\left(\mathcal{T}_{\text {bill }}\right)$.

(DOC)

Table S2 Linear mixed models describing surface temperature of the bill base $\left(\mathcal{T}_{\text {base }}\right)$.

(DOC)

Table S3 Linear mixed models describing heat loss through the bill $\left(Q_{\text {bill }}\right)$.

(DOC)

Table S4 Linear mixed models describing heat loss through the bill as a percent of heat of heat lost through all body surfaces (percent $Q_{\text {bill) }}$.

(DOC)

Table S5 Linear mixed models describing the surface temperature of the body $\left(T_{b o d y}\right)$.

(DOC)

Table S6 Linear mixed models describing the surface temperature of the legs $\left(\mathcal{T}_{\text {legs }}\right)$.

(DOG)

Table S7 Linear mixed models describing relative humidity. (DOG)

Text S1 Analysis of activity data.

(DOG)

\section{Acknowledgments}

Experiments were conducted under US Fish and Wildlife Service permit and NZP-ACUC 11-05. Sara Gonzales assisted with bird care. Nels Johnson of the Virginia Tech Laboratory for Interdisciplinary Statistical Analysis provided statistical advice.

\section{Author Contributions}

Conceived and designed the experiments: RG RMD VC GT. Performed the experiments: VC RMD RG. Analyzed the data: RG RMD VC GT. Contributed reagents/materials/analysis tools: RG VC. Wrote the paper: RG RMD VC GT. 
5. Giuliano M, Griggio M, Pilastro A (2002) The geographical distribution of populations of the large-billed subspecies of reed bunting matches that of its main winter food. Biol J Linn Soc 75: 21-26.

6. Bowman RI (1961) Morphological differentiation and adaptation in the Galápagos finches. Berkeley and LosAngeles: University of California Publications in Zoology.

7. Boag PT, Grant PR (1981) Intense natural selection in a population of Darwin's finches. (Geospizinae) in the Galapagos. Science 214: 82-85.

8. Pulliam HR, Enders F (1971) The feeding ecology of five sympatric finch species. Ecology 52: 557-566.

9. Herrel A, Podos J, Huber SK, Hendry AP (2005) Bite performance and morphology in a population of Darwin's finches: implications for the evolution of beak shape. Funct Ecol 19: 43-48.

10. Badyaev AV, Young RL, Oh KP, Addison G (2008) Evolution on a local scale: developmental, functional, and genetic bases of divergence in bill form and associated changes in song structure between adjacent habitats. Evolution 62: 1951-1964.

11. Allen JA (1877) The influence of physical conditions in the genesis of species. Radical Review 1: 108-140.

12. Rensch B (1938) Some problems of geographical variation and species formation. Proc Linn Soc Lond 150: 275-285.

13. Snow DW (1954) Trends in geographical variation in Palaearctic members of the genus parus. Evolution 8: 19-28.

14. Symonds MRE, Tattersall GJ (2010) Geographical variation in bill size across bird species provides evidence for Allen's rule. Am Nat 176: 188-197.

15. VanderWerf EA (2012) Ecogeographic patterns of morphological variation in elepaios (Chasiempis spp.): Bergmann's, Allen's, and Gloger's rules in a microcosm. Ornithol Monogr 73: 1-34.

16. Grant PR (1965) The adaptive significance of some size trends in island birds. Evolution 19: 355-367.

17. Walsberg GE, King JR (1978) Relationship of external surface area of birds to skin surface area and body mass. J Exp Biol 76: 185-189.

18. Matthysen E (1989) Seasonal variation in bill morphology of nuthatches Sitta europaea: Dietary adaptations or consequences. Ardea 77: 117-125.

19. Lucas AM, Stettenheim PR (1972) Avian anatomy: integument. Washington, DC: U.S. Agricultural Research Service, U.S. Government Printing Office

20. Van Hemert C, Handel CM, Blake JE, Swor RM, O'Hara TM (2012) Microanatomy of passerine hard-cornified tissues: Beak and claw structure of the black-capped chickadee (Poecile atricapillus). J Morphol 273: 226-240.

21. Hagan AA, Heath JE (1980) Regulation of heat loss in the duck by vasomotion in the bill. J Therm Biol 5: 95-101.

22. Scott GR, Cadena V, Tattersall GJ, Milsom WK (2008) Body temperature depression and peripheral heat loss accompany the metabolic and ventilatory responses to hypoxia in low and high altitude birds. J Exp Biol 211: 1326-1335.

23. Tattersall GJ, Andrade DV, Abe AS (2009) Heat exchange from the toucan bill reveals a controllable vascular thermal radiator. Science 325: 468-470.

24. Greenberg R, Danner RM, Olsen BJ, Luther D (2012) High temperatures explain bill size in salt marsh sparrows. Ecography 35: 146-152.

25. Nudds R, Oswald S (2007) An interspecific test of allen's rule: evolutionary implications for endothermic species. Evolution 61: 2839-2848.

26. Speakman JR, Król E (2010) Maximal heat dissipation capacity and hyperthermia risk: neglected key factors in the ecology of endotherms. J Anim Ecol 79: 726-746.

27. Scholander PF (1955) Evolution of climatic adaptation in homeotherms. Evolution 9: 15-26.

28. Bartholomew GA, Cade TJ (1963) The water economy of land birds. Auk 80: 504-539.
29. Dawson WR (1982) Evaporative losses of water by birds. Comp Biochem Phys A 71: 495-509.

30. Williams JB, Tieleman BI (2005) Physiological adaptation in desert birds. BioScience 55: 416-425.

31. Wolf BO, Walsberg GE (1996) Respiratory and cutaneous evaporative water loss at high environmental temperatures in a small bird. J Exp Biol 199: 451-457.

32. Greenberg R, Olsen BJ (2010) Bill size and dimorphism in tidal-marsh sparrows: island-like processes in a continental habitat. Ecology 91: 2428-2436.

33. Grenier JL, Greenberg R (2005) A biogeographic pattern in sparrow bill morphology: Parallel adaptation to tidal marshes. Evolution 59: 1588-1595.

34. Blaxter K (1986) Energy metabolism in animals and man. Cambridge: Cambridge University Press.

35. Ward S, Slater PJB (2005) Raised thermoregulatory costs at exposed song posts increase the energetic cost of singing for willow warblers Phylloscopus trochilus. J Avian Biol 36: 280-286.

36. Haynie DT (2001) Biological Thermodynamics. Cambridge: Cambridge University Press.

37. Baudinette RV, Loveridge JP, Wilson KJ, Mills CD, Schmidt-Nielsen K (1976) Heat loss from feet of Herring Gulls at rest and during flight. Am J Phys 230: 920-924.

38. Phillips PK, Sanborn AF (1994) An infrared, thermographic study of surface temperature in three ratites: ostrich, emu and double-wattled cassowary. J Therm Biol 19: 423-430.

39. Buchholz R (1996) Thermoregulatory role of the unfeathered head and neck in male wild turkeys. Auk 113: 310-318.

40. Yarbrough C (1971) The influence of distribution and ecology on the thermoregulation of small birds. Comp Biochem Phys A 39: 235-266.

41. Johansen K, Millard RW (1973) Vascular responses to temperature in foot of Giant Fulmar, Macronectes giganteus. J Comp Physiol 85: 47-64.

42. Millard RW, Reite OB (1970) Peripheral vascular response to norepinephrine at temperatures from 2 to 40 degrees C. J Appl Physiol 38: 26-30.

43. Patten MA, Pruett CL (2009) The Song Sparrow, Melospiza melodia, as a ring species: patterns of geographic variation, a revision of subspecies, and implications for speciation. Syst Biodivers 7: 33-62.

44. Ehrenfeld JG (1990) Dynamics and processes in barrier island vegetation. Aquat Sci 2: $437-480$

45. Hesp PA (1991) Ecological processes and plant adaptations on coastal dunes. J Arid Eviron 2: 165-191.

46. Mitchell JW (1976) Heat transfer from spheres and other animal forms. Biophys J 16: $561-569$.

47. Seamans T, Hamershock D, Bernhardt G (1995) Determination of body density for twelve bird species. Ibis 137: 424-428.

48. Bates D, Maechler M, Bolker B (2011) lme4: Linear mixed-effects models using S4 classes. 0.999375-39 ed2011. Available: http://r-forge.r-project.org/R/ ?group_id =60. Accessed 2012 Jun 29.

49. R Development Core Team (2011) R: A language and environment for statistical computing. Vienna, Austria: R Foundation for Statistical Computing. Available: http://www.r-project.org/. Accessed 2012 Jun 29.

50. Zuur A, Ieno E, Walker N, Saveliev A, Smith G (2009) Mixed Effects Models and Extensions in Ecology with R. New York: Springer.

51. Burnham KP, Anderson DR (2002) Model selection and multimodel inference: A practical information-theoretic approach. 2nd ed. New York: SpringerVerlag.

52. Mazerolle MJ (2011) AICcmodavg: Model selection and multimodel inference based on (Q)AIC(c). R package version 1.17 ed2011. Available: http://cran.rproject.org/web/packages/AICcmodavg/index.html. Accessed 2012 Jun 29. 